Department of

Economics and Finance

Working Paper No. 09-13

Elisabetta Iossa and David Martimort

2

The Theory of Incentives Applied to the Transport Sector

February 2009 


\title{
The Theory of Incentives
}

\section{Applied to the Transport Sector ${ }^{1}$}

\author{
Elisabetta Iossa ${ }^{2}$ and David Martimort ${ }^{3}$
}

February 4, 2009

\begin{abstract}
Building upon Iossa and Martimort (2008), we study the main incentive issues and the form of optimal contracts for Public Private Partnerships (PPPs) in transports. We present a basic model of procurement in a multitask environment in which a risk-averse firm chooses unobservable efforts in infrastructure and service quality. We begin by analyzing the effect on incentives and risk transfer of bundling building and operation into a single contract. We consider the factors that affect the optimal allocation of demand risk and their implications for the choice of contract length. We discuss the dynamics of PPP contracts and how the risk of regulatory opportunism affects contract design and incentives.
\end{abstract}

JEL Classification: D8, H54, H57, L5, L91.

Keywords: Contracting out, public-private partnerships, public-service provision, transport.

\footnotetext{
${ }^{1}$ We wish to thank Emile Quinet and Richard Lindsey who invited us to contribute this chapter and provided extensive comments on a first version that improved exposition. We also wish to thank Antonio Estache for helpful suggestions.

${ }^{2}$ Brunel University and University of Rome Tor Vergata, CEDI and CMPO.

${ }^{3}$ Toulouse School of Economics (IDEI and GREMAQ) and EHESS.
} 


\section{Introduction}

Efficient transport infrastructures is crucial to economic development. Improvements in transport networks enhance competitiveness and boost economic growth by raising the marginal product of labour and capital and thus the overall efficiency of the productive mix (see e.g. Aschauer, 1989). Furthermore, as firms tend to locate in areas offering wider access to supply and demand markets, transport infrastructures enhance some locations attractiveness towards new productive settlements which result in self-reinforcing growth mechanisms (see Messina, 2008).

But how should transport infrastructure be procured and financed? Substantial institutional changes have taken place in the European Public Transport scene over the past 20 years. The use of contracting has been spreading over all transport sectors and greater risk transfer to private operators has been achieved. At the same time, competitive tendering practices have gradually been implemented to replace direct awarding of contractual rights and a number of municipal operators have been privatized.

The spread of public-private partnerships (hereafter abbreviated as PPPs) is a significant part of this trend. Under a PPP, a public authority (local or central government or a government agency) enters a long-term contractual arrangement with a private supplier (or a consortium of private suppliers) for the delivery of some services. The supplier takes responsibility for building infrastructure, financing the investment and then managing and maintaining the assets. At the end of the contract, assets are transferred to the government under terms agreed to in the contract. Payments to the contractor can either come from the users of the service or from the government in the form of shadow tolls.

In Europe, transport infrastructures, such as the oldest highways and rail networks, have traditionally been built on the basis of public funding, whether regional, national or Community originated. Most of the road or rail projects currently underway also follow this pattern. The PPP approach was pioneered in the UK by the Private Finance Initiative (PFI) in 1992 (Grout, 1997). The first transport project was the Isle of Skye bridge, connecting the Isle of Sky to the mainland. PPPs have since been used for a number of urban transportation projects and for some of the biggest infrastructure projects and isolated links (tunnels bridges) throughout Europe, such as the Eurotunnel and London Underground. Private involvement in highways construction and management has also increased substantially in the last years following sector reforms in France, Italy and Spain and the PPP approach is now being adopted to build transport infrastructure also in Eastern European countries (EIB, 2004). In the U.S., PPPs in the transport sector were developed in the 70's for inner-city infrastructure (Rosenau, 2000) and are currently used for projects involving highways and road transportation (CBO, 2007). In Australia, New South Wales was the early adopter, opening the way for a series of toll roads in the 1990s.

Developing countries witnessed a dramatic increase in how the private sector was involved in building and funding infrastructure activities over the last 20 years. Since the 1990s, the private sector has invested 180 billions U.S. Dollars in transport infrastructure and by 2006 a total of 1000 private projects had been initiated. Latin America accounts 
for 40 percent of all transactions. By (sub)sectors, the majority are road projects, followed by the railroad sector. In terms of the size of investment, the road and railroad sectors amount to 47 percent and 20 percent of private participation experiences in developing countries, respectively (Estache, Guash, Imi and Trujillo, 2008). According to the Private Participation in Infrastructure Project (PPIAF) Database, transport was the sector with the fastest growth of projects with private participation in 2005-06 worldwide. The investment doubled in 2005 and rose another 30 percent in 2006, to almost $\$ 30$ billion. Substantially higher investment were undertaken in airports, railways, and seaports, though investment in roads declined. The most common type of project was concession, followed by greenfield projects.

Despite this growth, evidence on PPP performance in transportation sector remains mixed. On the one hand, as reported by the EC White Paper (2006), private financing of infrastructure has so far received little attention in Europe from private investors, especially cross-border infrastructures on which profits, often low, are by no means certain. Furthermore, traffic/revenue forecasts have often been overoptimistic, leading to costly renegotiation, and numerous instances where projects have been abandoned or taken in house (Guash, 2004). Opportunistic renegotiations lead by the private operators were pervasive in Latin America's highway projects in the 80s for example. More recently, in the concession to design, finance, build, operate and transfer the 43-km M1-M15 motorway in Hungary for example, many commercial vehicles kept using an alternative untolled road. This lead to a debt default by the private partner and to both the concession and debt obligations taken over by the public-sector party (European Commission, 2004). In the UK, the controversial London Underground PPP project saw one of the three contractors filing for bankruptcy leaving taxpayers to pay the bill and the service taken in house. The Eurotunnel Project suffered a long history of cost overruns. In Australia, some big projects failed, such as the Cross City Tunner which went into receivership in December 2006 owing $\$ 570 \mathrm{~m}$ (Private Finance Journal, September 2008).

Observers give different explanations to government's support for PPPs agreements. First, the private finance aspect of PPPs has allowed the public sector to finance the construction of infrastructure "off the balance sheet" and to overcome constraints on public spending set by the Maastricth Treaty (IPPR, 2001). Establishing the accounting treatment of PPPs has indeed been a particularly important issue in EU countries. ${ }^{1}$ Second, some governments act allegedly under the belief that private operators are able to deliver services more efficiently than public operators. Whilst empirical evidence has shown that private firms are often more efficient than state ones, many instances also exist where the opposite holds. ${ }^{2}$

In this paper, we provide a theoretical framework to identify circumstances in which the main characteristics of PPP arrangements are suitable to provide incentives for the private providers in the transport sector. For this purpose we characterize PPPs in transport by four main features: (i) tasks bundling, (ii) high risk transfer, (iii) long-term

\footnotetext{
${ }^{1}$ Eurostat has recently made a decision (news release 18/2004) on the accounting of PPPs with the aim to ensure homogeneity across member states and limit accounting tricks made to comply with the rules of the Stability and Growth Pact.

${ }^{2}$ For a survey of empirical studies on privatization and contracting out see Megginson and Netter (2001).
} 
contracting and (iv) private finance. ${ }^{3}$

(i) Task bundling. A PPP typically involves the bundling of the design, building, finance, and operation of the project, which are contracted out to a consortium of private firms that is responsible for all aspects of services.

(ii) Risk transfer. Compared to traditional procurement, a PPP contract involves a greater transfer of risk (e.g. construction risk and operational risk) and responsibility to the contractor.

(iii) Long-term contracting. A PPP contract is a long-term contract lasting typically 20 to 35 years.

(iv) Private finance is a substantial feature of the contract; users charges are set to reward private investors.

To capture those features, we present a simple model of procurement in a multitask environment where the agent not only manages existing assets necessary to provide the service but also may design, build and finance these assets.

We already know from the seminal work on privatization by Sappington and Stigliz (1987) but also from more basic results in the Theory of Incentives (see the textbook treatment in Laffont and Martimort, 2002) that a good understanding of the cost of delegating a task or service to the private sector can only be obtained in a world where this task delegation is impeded with agency costs. Those agency costs are often due to the non-observability of the efforts undertaken on the delegated tasks: the case of moral hazard. Intuitively, when any effort that could improve the returns on the delegated task is non-observable, providing enough incentives to the private sector for completing that task requires to let him enjoy more of the returns. Such delegation is costless when the firm is risk neutral. Indeed, the principal can "sell" the activity to the delegatee for a fixed fee equal to its expected return. However, such delegation is definitively more costly when the firm is risk-averse and those returns are uncertain since the contract should also bring insurance to the firm. This trade-off between incentives and insurance is the key source of agency costs. Optimal contracts in such an environment are intermediate between fixed-price contracts that have good incentive properties and cost-plus contracts that provide insurance. Of course, those lessons are more intricate as the environment gets more complex like in a PPP context, because of dynamic considerations or because public authorities are not only concerned with delegating the management of a project but may be also the building of infrastructures. Analyzing such complex delegation patterns through the lenses of the Theory of Incentives is the perspective we took in Iossa and Martimort (2008). In the present paper, we apply this methodology to discuss contractual and incentive issues for PPPs in the transport sector.

In Section 3, we use the basic model to show how bundling of project phases into a single contract can be optimal to induce contractors to look at the long-term performances of the asset and to invest in asset quality. Further, we show that bundling goes hand in hand with more risk transfer to the contractor, which provides a rationale for both bundling and risk transfer to be key features of PPP arrangements.

In Section 4 we focus on the choice of contract length for financially-free standing projects where users' fees represent all of the contractor's revenue. We show that relying

\footnotetext{
${ }^{3}$ See Estache, Juan and Trujillo (2008) in this volume for a more in depth discussion of the main features of PPP in transports.
} 
only on private finance can lead to distortions in the choice of the length of the contract which result in reduced incentives for the contractor to invest in infrastructure quality.

Section 5 studies the dynamics of PPP contracts. We start by analyzing the trade off between investment and maintenance and the impact this has on risk allocation over time. When the public authority has a strong commitment power, we show that the optimal long-term contract entails increasing incentives over time to foster the renewal of investment. Cost-plus contracts arise in early periods whereas fixed-price agreements are expected close to the end of the contract.

In Section 6 we extend the analysis of the dynamics of PPP contracts to the case where commitment is limited, governance is weak and political risk makes renegotiation likely. This allows us to discuss the effect of institutional quality on the performance of PPPs. In particular, we show that the risk of regulatory opportunism raises the potential benefit of cost-plus contracts.

Section 7 summarizes our conclusions.

\section{The Basic Model}

A government or public entity (referred to as $G$ ) relies on a private firm or consortium (referred to as $F$ ) to provide the transportation services for society. Production of the service requires a multi-stage project involving not only building but also managing the transport infrastructure. Payments to the contractor come from users of the service. So for example for highways the contract charges a toll to users (as in Italy or France). For airports, the contractor receives a landing fee from airlines and a rental charge from lessees (say airport shops). For railways, the contractor charges train operating companies for access to the rail network and passengers pay train operating companies for the service. ${ }^{4}$

Demand for the service is stochastic and influenced not only by the quality of the infrastructure but also by the effort exerted by $F$ when providing the service. So for example the benefit enjoyed by users of motorways depends on the route safety and thus on the quality of the highway as well as on maintenance effort. In railways, transport demand depends on the quality and comfort of trains, on service reliability, on-the train services, the efficiency of the ticketing system and so on. Major risks affect transport projects at operating stage which include technology, traffic/revenue risks; interest rate and foreign exchange risks; "force majeure" risks. Even when there is a reasonable level of confidence in forecasts, demand can be dramatically affected by competition from other modes or facilities, changing user needs, and macroeconomic conditions. In toll roads projects for example uncertainty often comes from the availability of alternative untolled roads.

We capture the above features by assuming that users have an inelastic demand for the service up to some price level $p_{0}$ which is given by:

$$
D(p)= \begin{cases}d_{0}+d a+e+\eta & \text { if } p \leq p_{0} \\ 0 & p>p_{0} .\end{cases}
$$

\footnotetext{
${ }^{4}$ We do not explicitly model here the case where the contractor receives a shadow toll from the government (as for highways in the U.K.) but the analysis easily extends to that case, assuming that demand is verifiable and can be contracted upon.
} 
where $a$ is the effort in infrastructure quality, whilst $e$ is the effort in service quality. The marginal benefits of the agents' efforts are positive, in particular $d \geq 0$ and $d_{0} \geq 0$ denotes some base level of demand that is obtained even without any effort. These quality efforts have disutility counted in monetary terms of $\frac{a^{2}}{2}, \frac{e^{2}}{2}$ respectively, with no (dis-)economies of scope between efforts. Exogenous demand risk is captured by the random variable $\eta$ which is normally distributed with zero mean and variance $\sigma^{2}$.

The firm's expected revenue is therefore:

$$
E_{\eta}(R)=p_{0} E_{\eta}\left(\max \left\{d_{0}+d a+e+\eta, 0\right\}\right) \approx p_{0}\left(d_{0}+d a+e\right),
$$

where the approximation above holds when $\sigma^{2}$ is small enough compared to the base level of demand $d_{0}$.

For simplicity, we assume away any incentive problem on the cost side and assume zero marginal costs of providing the services.

Delegation of services to the private sector takes place in a moral hazard environment so that both $a$ and $e$ are nonverifiable. We focus on moral hazard as the sole source of incentive problems as this fits well with the observation made by Bajari and Tadelis (2001) that, in many procurement contexts, the buyer and the seller face the same uncertainty on costs and demand conditions Unless stated otherwise, only the realized demand $D$ is observable and can be used ex ante at the time $G$ and $F$ contract together.

In practice many aspects of service quality in transport concessions are observable and verifiable by third-parties. This is the case for example of train punctuality and rail crash rates in rail concessions, travel time variability in bus concessions and asphalt quality, congestion levels or mortality rates in highway concessions. For these aspects of quality, the PPP contract should specify quality targets and then use bonuses and penalties to incentivize the contractor to invest so as to meet these targets. This is indeed what we generally observe in practice where deductions are applied for example when train punctuality falls short of contractually agreed levels. In these settings, if the investment in quality is contractible, adequate penalties for noncompliance can suffice to ensure that contractual obligations are met. When instead investment is noncontractible, a moral hazard problem arises. This problem could be studied within our framework by simply reinterpreting $D$ as a quality indicator and $\beta$ as an incentive payment (within a linear incentive scheme) linked to quality levels.

Keeping here our focus on noncontractible quality, we assume that the risk-neutral government $G$ maximizes an expected social welfare function, defined as the social benefit of the service net of its costs and of the payment made to $F .^{5}$ The firm $F$ also maximizes expected profit but it is risk-averse with constant absolute degree of risk-aversion $r>0$. The assumption of risk-neutrality for $G$ fits well the case where the transport project is small relatively to the share of the overall budget or even the unique project under a

\footnotetext{
${ }^{5}$ This assumption simplifies presentation and stresses that the fact that the risk-premium necessary to induce the firm's participation has the highest possible cost. Having a redistributive objective with a weight less than one for the firm's profit in the government's objective function or introducing a positive cost of public funds would also give us the same insights at the cost of an increased complexity in the modeling. Note also that our model can easily accommodate the possibility of externalities -be they positive on employment say, or negative on environment- include them into the net social value of the firm's activity.
} 
transport agency's responsability. ${ }^{6}$ The assumption of risk-aversion for $F$ captures the fact that a PPP project might represent a large share of this firm's activities so that the firm can hardly be viewed as being fully diversified.

- Benchmark: Suppose that efforts are observable and contractible. $G$ can run a competitive auction to attract potential service providers. $G$ has all bargaining power ex ante and chooses a fee for the service provider that makes him just indifferent between producing the service or getting his outside option normalized at zero. At the first-best, $F$ is fully insured by $G$ and thus bears no risk. The contract forces $F$ to choose the first-best efforts defined as:

$$
\left(a^{F B}, e^{F B}\right)=\arg \max _{(a, e)} p_{0}\left(d_{0}+d a+e\right)-\frac{a^{2}}{2}-\frac{e^{2}}{2}=\left(d p_{0}, p_{0}\right) .
$$

The first-best quality-enhancing effort $a^{F B}$ trades off the marginal social value of that effort, given by its impact on revenues $\left(d p_{0}\right)$, with its marginal cost $(a)$. The service quality effort $e^{F B}$ trades off the marginal benefit of increasing revenues $\left(p_{0}\right)$ with its marginal monetary disutility $(e)$. The offered contract is then defined as a pair $\left(a^{F B}, e^{F B}\right)$, and a reward such as the firm's expected profit is zero. The observability of $a$ and $e$ allow to contract on them. Under those conditions, welfare is maximized. The case where $a$ and $e$ are not observable is dealt with in Section 3.

\section{The Benefits of Bundling}

The main feature of a PPP is the bundling of various phases of contracting. In a typical $\mathrm{PPP}$, design $(\mathrm{D})$, building $(\mathrm{B})$, finance $(\mathrm{F})$ and operation $(\mathrm{O})$ of the project (this is the so-called "DBFO model") are contracted out to a consortium of private firms. This consortium generally includes a construction company and a facility-management company and it is responsible for all aspects of the service. ${ }^{7}$ So for example, a PPP contract may provide for the contractor to construct, finance, manage and maintain a highway section, a tram line, a light rail, an underground line or a bridge. The contractor recoups his initial investment either through user charges or through a direct payment from the government (or any of its agencies) or through a combination of both.

In this section we study the effect of bundling on the contractor's incentives to make nonverifiable investment in infrastructure quality and effort in service quality, which increase the demand for the service.

Unbundling: Under traditional contracting, $G$ approaches first a builder and then a separate operator. The operator receives a revenue-sharing rule $t(R)$. We follow Holmström and Milgrom (1991) and restrict the analysis to linear rules of the form $t(R)=\alpha+\beta R$.

\footnotetext{
${ }^{6}$ In the case of a large country's government, the existing deadweight loss in the cost of taxation (say the cost of taxation is convex) may as well introduce a behavior towards risk for the government if the project represents a large share of the budget. See Lewis and Sappington (1995) and Martimort and Sand-Zantman (2007) who analyze the consequences of having risk-averse local governments for contract design. Often, the basic insight of those models is that risk-aversion on the principal's side reduces incentive distortions.

${ }^{7}$ Variations of the DBFO contract include Design-Build-Operate (DBO), Build-Operate-Transfer (BOT), Build-Own-Operate-Transfer (BOOT), Build-Lease-Operate-Transfer (BLOT), etc...
} 
The fee $\alpha$ is a fixed payment to the firm (or subsidy) paid upfront. The coefficient $\beta$ is meant for the share of those profits which are left to the firm; the share $1-\beta$ being kept by the government. So, in a payment mechanism solely based on user charges, the contractor receives its revenues directly trough charges on the end users of the infrastructure facility and bears all demand risk. This corresponds to the case $\alpha=0$ and $\beta=1$. Instead, with a payment mechanism based on availability, the government rewards the contractor for making the service available but the payment is independent of the actual service usage. This corresponds to the case where $\alpha>0$ and $\beta=0$ so that the contractor's reward is fixed and the government retains all demand risk. The other cases fall between these two extreme options.

To simplify presentation and fit with the empirical evidence for transport, we rule out the theoretical possibility that the builder obtains an incentive payment that depends on the realized demand $D$, and assume instead, that he receives a fixed payment. ${ }^{8}$

Since his fixed payment cannot reward the quality enhancing effort put into the design of the project, the builder does not exert any effort:

$$
a_{u}=0
$$

Turning now to the operator who is willing to maximize the certainty equivalent of his expected utility given the builder's own effort, his incentives constraint can be written as:

$$
e=\arg \max _{\tilde{e}} \alpha+\beta p_{0}\left(d_{0}+\tilde{e}\right)-\frac{\tilde{e}^{2}}{2}-\frac{r \sigma^{2} \beta^{2} p_{0}^{2}}{2}=\beta p_{0}
$$

Increasing $\beta$ raises demand-enhancing effort, but as more operational risk is then transferred to $F$ the risk-premium $\frac{r \sigma^{2} \beta^{2}}{2}$ increases too. Assuming that $G$ has all the bargaining power ex ante with both the builder and the operator, he can extract all their rent and just leave them indifferent between providing the service and getting their outside opportunities normalized at zero. In particular, the fee $\alpha$ is just set to cover the risk-premium that must be paid to have the risk-averse operator bearing some operational risk as requested for incentive reasons.

Finally, $G$ just maximizes social welfare taking into account the incentive constraints (2) and (3) and the total benefit and cost of effort, including the risk-premium. This yields the following expression of $G$ 's problem:

$$
\max _{e} p_{0}\left(d_{0}+e\right)-\frac{e^{2}}{2}-\frac{r \sigma^{2} \beta^{2} p_{0}^{2}}{2} \text { subject to }(3) .
$$

This gives the following expression of the second-best effort and marginal reward:

$$
e_{u}^{S B}=\beta^{S B} p_{0}=\frac{p_{0}}{1+r \sigma^{2}}
$$

\footnotetext{
${ }^{8}$ The justification for this assumption is twofold. First, $G$ may have a limited ability to commit to future rewards for the builder and be unable to delay payment for the delivery of the infrastructure. Second, there might be the possibility of collusion between $G$ and the operator to exaggerate the contribution of the operator to cost-reducing activities and underestimate that of the builder.
} 
We observe that $\beta^{S B} \in(0,1)$ which captures the fact that the risk-averse firm only receives a fraction of the overall profit for insurance reasons and undersupply effort below its firstbest value. Finally, the fixed-payment $\alpha^{S B}$ is determined so that the firm breaks even in expectation.

Because providing incentives requires the agent to bear more risk and this is socially costly, the second-best effort is less than its first-best level. As it is standard with this linear-CARA model, an increase in demand risk (making $\sigma^{2}$ larger) also means that the trade-off between insurance and incentives is tilted towards low-powered incentives. ${ }^{9}$

For further references, note that social welfare under unbundling can be written as:

$$
W_{u}^{S B}=p_{0} d_{0}+\frac{p_{0}^{2}}{2\left(1+r \sigma^{2}\right)} .
$$

From this characterization of the incentive constraint, we get:

Result 1 The optimal payment mechanism comes closer to be based on user charges only when risk-aversion and demand risk are small (high-powered incentives). The payment mechanism moves towards being based on availability only when risk-aversion and demand uncertainty are large (low-powered incentives).

Transferring demand risk to the contractor gives him incentives to boost demand and raise consumer surplus but it costs the government in terms of a higher risk-premium. The optimal payment mechanism trades off incentives and insurance. Further, both the power of the incentive scheme $\beta$ and investment $a^{S B}$ rise with $d$. That is, for PPPs in sectors such as transport, where demand levels are affected by the contractor's action (thus $d$ is high), demand risk should be borne mainly by the contractor.

Bundling: Under bundling both the building of the infrastructure and the operational phase are in the hands of a consortium which chooses both $a$ and $e$ to maximize

$$
(e, a)=\arg \max _{(\tilde{e}, \tilde{a})} \alpha+\beta p_{0}\left(d_{0}+d \tilde{a}+\tilde{e}\right)-\frac{\tilde{a}^{2}}{2}-\frac{\tilde{e}^{2}}{2}-\frac{r \sigma^{2} \beta^{2} p_{0}^{2}}{2} .
$$

Taking into account the additional non-negativity constraint $a \geq 0$, we obtain the following incentive constraints:

$$
e=\beta p_{0} ; \text { and } a=\beta p_{0} d=d e
$$

Note in particular that the effort $e$ follows the same formula as in the case of unbundling. This is no longer the case for $a$ which changes thanks to the positive externality that is internalized under bundling.

\footnotetext{
${ }^{9}$ So far, our analysis has assumed away any cost of public funds. Suppose that any transfers from and payments to the government are weighted by a factor $1+\lambda$ where $\lambda$ is the positive cost of public funds. Then, the objective function is essentially the same as above if the social benefit of the project becomes $\frac{b_{0}+b a}{1+\lambda}$. Intuitively, counting more any extra euro given to the firms and raised through taxation, is equivalent to reduce the social value of the project. As a result, since $e_{u}^{S B}$ given by (4) does not depend on the social benefit of the project (and any externality that may be incorporated into it), the power of incentives under unbundling remains unchanged as the cost of public funds becomes positive. The benefits of bundling tasks that we will highlight below will be de facto reduced but remain still positive. A second by-product of this discussion is that the issue of whether to bundle or not tasks is independent of whether public funds are costly or not.
} 
A consortium internalizes somewhat the impact of building a high quality infrastructure because it increases its revenues. Moving towards more risk transfer also raises incentives on infrastructure quality; an objective which cannot be directly achieved by the public authority since that quality is hardly contractible.

Finally, taking into account how the firm chooses investment in infrastructure quality and effort, $G$ solves the following problem:

$$
\max _{(a, e)} p_{0}\left(d_{0}+d a+e\right)-\frac{a^{2}}{2}-\frac{e^{2}}{2}-\frac{r \sigma^{2} \beta^{2} p_{0}^{2}}{2} \text { subject to }(6) .
$$

which gives the following equilibrium levels of effort

$$
e_{b}^{S B}=\frac{p_{0}\left(1+d^{2}\right)}{1+d^{2}+r \sigma^{2}} \text { and } a_{b}^{S B}=\frac{p_{0} d\left(1+d^{2}\right)}{1+d^{2}+r \sigma^{2}}
$$

The level of welfare under bundling is given by

$$
W_{b}^{S B}=p_{0} d_{0}+\frac{p_{0}^{2}\left(1+d^{2}\right)}{2\left(1+d^{2}+r \sigma^{2}\right)} .
$$

Result 2 Bundling strictly dominates unbundling: $W_{b}^{S B}>W_{u}^{S B}$. The welfare gain from bundling increases with the magnitude of the externality $d$ :

$$
\frac{\partial}{\partial d}\left(W_{b}^{S B}-W_{u}^{S B}\right)>0 .
$$

With bundling there is a positive infrastructure quality-enhancing effort and an increase in cost-reducing effort. PPP projects are associated with higher powered incentives and more operational risk being transferred to the private sector:

$$
e_{b}^{S B}=\beta_{u}^{S B} p_{0}=e_{u}^{S B} ; a_{b}^{S B}=\beta_{b}^{S B} p_{0} d>a_{u}^{S B}
$$

Bundling induces the agent to internalize the effect of his quality-enhancing investment $a$ on the share of revenues that he bears at the operational stage. This unambiguously raises welfare, and the stronger the effect of infrastructure quality on revenues, $d$, the greater the benefit of bundling. Furthermore, bundling shifts more risk to $F$ and brings the additional benefit of increasing its incentives to invest in asset quality. Thus, moving from traditional procurement to PPP changes renvenue-sharing rules: bundling and risk transfer go hands in hands under PPP whereas unbundling and less risk sharing contracts are more likely under traditional procurement. This rationalizes existing evidence that PPP projects are characterized by more risk transfer and thus greater risk-premia than traditional procurement.

Literature : Two strands of the literature on PPPs have emphasized the multitask nature of the procurement problem when building and managing assets are at stake. Hart (2003) built on Hart, Shleifer and Vishny (1997) provided a model where the sole source of incentives is ownership. A builder can perform two kinds of investment (productive and unproductive) which may both reduce operating costs, although only the productive investment raises also the benefit of providing the service. Under traditional procurement, 
the builder cannot internalize the impact of his effort either on benefits or on costs and, as a result, implements too little of the productive investment but the right amount of the unproductive one. Under PPP, the builder internalizes partly the impact of his productive investment whereas he also exerts too much of the unproductive one. Turning to the case where ownership concerns a public good and still using the property rights approach, Besley and Ghatak (2001) showed that ownership should lie in the hands of that player with the highest valuation for the public good, explaining thereby that non-governmental organizations may be given property rights. Finally, Francesconi and Muthoo (2006) considered the case of impure public goods and, in a model where each party may have control rights on a subset of decisions, showed that shared authority can be optimal in case the parties' investments are comparable.

Bennett and Iossa (2006a) studied the desirability of bundling project phases and of giving ownership to the investor. In their model innovations are non-contractible ex ante but verifiable ex post. Ownership of the asset gives control right to the owner to decide whether to implement quality enhancing or cost-reducing innovation proposed by the investor. It is shown that the hold-up problem is less severe under PPP, compared with traditional procurement, when there is a positive externality between the building and managing stages. With a negative externality the opposite can hold. Further public ownership acts as a commitment for the government to renegotiate and share with the investor the surplus from the implementation of the innovation. Private ownership is however optimal for generic facilities with high residual value.

Martimort and Pouyet (2008) built a model where both the quality of the infrastructure and operating costs are contractible. Agency costs are lower under a PPP when there is a positive externality between building and managing assets compared with traditional procurement. Granting ownership is an imperfect way of aligning incentives but, to a large extent, the important issue is not who owns the asset but instead whether tasks are bundled or not. That insight is developed in various extensions of their basic model allowing for risk-sharing as a motive for forming consortia, or political economy. In this respect, a common theme of their model and ours is that PPP comes with higher powered incentives which are prone to collusion and capture of public officials. When those institutional costs are taken into account, relying on PPP becomes less attractive.

Finally in Iossa and Martimort (2008) we build upon the above two models and provide a unified framework, with elements of both complete contracting and property rights, which highlights the positive effects of bundling in the presence of a positive externality and the negative ones in the presence of a negative externality.

Applications: Our results suggest that PPPs are likely to deliver efficiency gains when bundling has the potential to yield significant demand increase and when risk is effectively transferred to the private operator. A report commissioned by the Treasury Taskforce (Arthur Andersen and Enterprise LSE, 2000) estimated saving on a sample of PFI projects equal to $17 \%$, compared to traditional procurement. ${ }^{10}$ Evidence of successful PPP projects in transport also exists. For example, the TransMilenio bus transport project developed in 2000 in Bogotá achieved significant improvements in the efficiency, safety and environmental impact of the system. The $\$ 90 \mathrm{~m}$ PPP contract for the Washington DC metro lead to $600 \%$ increase in property values in the affected areas. The 30

\footnotetext{
${ }^{10}$ However, Pollock and Vickers (2000) question the Andersen report and argue that once outliers are excluded from the calculations the average saving is 6 per cent.
} 
year contract for Colombo port in Sri Lanka saw the construction of 3 container berths and 1 passenger berth whilst the port remained operational throughout; the throughput increased by $350 \%$ from 2000 to $2004 .{ }^{11}$ In the seven years following its privatization, the PPP operator for the Italian motorway network reported a fall by about $50 \%$ in mortality rates and an increase in the usage of electronic toll payment system by $227 \%{ }^{12}$

However, evidence of PPP failure are also recorded. Costs have escalated to record levels for the Channel Tunnel Raillink, the PPP operator for London Undergraund has gone bust and many PPP transport projects have failed to raise the interest of investors. Whilst warning against lack of comprehensive dataset, Blanc-Brude, Goldsmith and Välilä (2006) studied a sample of road projects financed by the EIB between 1990 and 2005 in all EU-15 countries plus Norway. They found that ex ante construction costs (i.e., costs before construction actually starts) are some $20 \%$ higher for PPP roads than for traditionally procured roads. The data does not reveal the actual (ex post) cost of the projects and thus whether risk transfer under PPP was effective in containing cost overruns.

In practice, PPPs are often employed out of a need for governments to use private finance for financing infrastructure. In Iossa and Martimort (2008) we showed that a potential benefit of private finance stems from the possibility that lenders bring in the expertise of outside financiers in evaluating risks. Outside financiers can condition how much repayment they request from the firm on the extra information they have on the contractor's effort. As the financial contract is made under a better information structure, the extra round of contracting with financiers has more benefits in terms of improved incentives than costs in terms of modified risk-sharing. In this respect, bundling the task of looking for outside finance (be it through outside equity or debt) and operating assets can improve on the more traditional mode of procurement where the cost of investment is paid through taxation and investment is not backed up by such level of expertise within the public sphere.

\section{Contract Length}

In this section, we focus on a cost of private finance that comes from the absence of a powerful means to provide incentives: government transfers. We consider the case of financially free standing projects, where there are no direct subsidies from the government to the firm. The firm must then cover its initial investment $I$ from the revenues it withdraws from charging user fees over the length $T$ of the contract. After date $T$, the PPP goes back under public ownership and the access toll is set at zero. In this setting, we analyze the determinants of the optimal contract duration when project revenues only come from charging users. To this purpose we assume that the shocks on the level of demand are drawn once for all whereas the cost of effort in infrastructure quality is sunk and borne once for all beforehand. For simplicity, we disregard effort in service quality.

With these assumptions in mind, intertemporal income smoothing for the firm leads to rewrite the firm's discounted stream of certainty-equivalent payoffs when choosing effort

\footnotetext{
${ }^{11}$ See the case studies and reports of the National Council for Public Private Partnerships (NCPPP), on http://www.ncppp.org/aboutus/index.shtml.

${ }^{12}$ See www.autostrade.it
} 
$a$ and making the investment $I$ as:

$$
\begin{gathered}
E_{\eta}\left(u\left(-I-\frac{a^{2}}{2}+\int_{0}^{T} p_{0}\left(d_{0}+d a+\eta\right) \exp (-\rho t) d t\right)\right) \\
=u\left(-I-\frac{a^{2}}{2}+(1-\exp (-\rho T)) p_{0}\left(d_{0}+d a\right)-\frac{r \sigma^{2}}{2}(1-\exp (-\rho T))^{2} p_{0}^{2}\right)
\end{gathered}
$$

where $\rho$ is the interest rate in the economy.

This immediately leads to the following moral hazard constraint:

$$
a=(1-\exp (-\rho T)) d p_{0}
$$

When government transfers cannot be used to provide incentives, higher investment in infrastructure quality can be induced either by raising the tariffs charged to users for the service, $p_{0}$, or by increasing the length of the contract, $T$. The longer the duration of the contract $T$, the greater the firm's investment since its benefits accrue over a longer period. Note that the term $1-\exp (-\rho T)$ plays the same role as $\beta$ in formula (3) above. Instead of directly sharing the revenue with the firm in each period, the government lets the firm enjoy all revenue but for a finite duration.

With no subsidies however the duration of the contract may have to serve also another purpose, namely that of ensuring that the revenues from the project over the whole duration of the contract are sufficient to cover the initial investment undertaken by the firm, that is:

$$
(1-\exp (-\rho T)) p_{0}\left(d_{0}+d a\right)-\frac{a^{2}}{2}-\frac{r \sigma^{2}}{2}(1-\exp (-\rho T))^{2} p_{0}^{2} \geq I .
$$

Consider the case (i) where the investment constraint (8) is slack, i.e., expected revenues over the duration of the contract are enough to cover the up-front investment. The second-best effort level that maximizes expected welfare is then easily obtained as:

$$
a^{S B}=\frac{d p_{0}}{1+r \sigma^{2}}=d p_{0}\left(1-\exp \left(-\rho T^{S B}\right)\right) .
$$

From which, we derive the optimal unconstrained length of the franchise as:

$$
T^{S B}=\frac{1}{\rho} \ln \left[1+\frac{1}{r \sigma^{2}}\right] .
$$

Thus, when the budget constraint is slack (at $a=a^{S B}$ ), the length of the contract is chosen for the sole purpose to create incentives for investment in infrastructure quality. We then obtain:

Result 3 Assume that the investment constraint is slack. Franchise lengths are shorter when discount rates are lower, in more uncertain environments or when risk-aversion is greater. 
As longer contracts are also riskier - future demand is more difficult to forecast - both higher demand risk and a greater degree of risk-aversion call for reducing the incentive power and for more insurance which is obtained by reducing the length of the contract. Thus in situations where demand volumes are volatile and difficult to forecast, the optimal contract duration is shorter than in sectors where demand is stable and predictable. An example in order is the case of motorways where franchises can be allowed before or after completion. The model predicts that, in the latter, franchise lengths should be shorter to take into account a greater uncertainty on future demand. Instead PPP contracts for the renovation of small transport networks (rather than construction of new ones), often entail little initial investment. When the state of the existing network is known, risk is low and the length of the contract can be set sufficiently long so as to boost quality investment.

Things change in case (ii) where the budget constraint is binding (at $a=a^{S B}$ ). Now the length of the contract must be chosen so as to guarantee that the stream of expected revenues coming from user charges is sufficient to cover the firm's investment as well as the risk-premium. Franchise length is then given by (8) where the inequality is now replaced by an equality. In big transport projects for new infrastructures, or in PPP contracts for renewal of transport networks that suffered from years of underinvestment (e.g. London Undergraund) when in public hands, finance constraints are generally binding.

To see the effect of a binding budget constraint, suppose that $T^{S B}$ is such that (8) does not hold. The length of the contract has to be modified to ensure that the firm breaks even, i.e. that the stream of future revenues is sufficient to cover the initial investment.. We get:

Result 4 Assume that the investment constraint is binding. Franchise lengths are shorter in more uncertain environments, when risk aversion is greater, when consumers' willingness to pay is greater ( $p_{0}$ greater), when investment is lower (I lower).

Those results have implications for the renegotiation of franchise contracts near bankruptcy. One should expect those renegotiation to increase the length of the contracts to secure investment. This is indeed what we observe in practice: Guash (2004) reports numerous instances where contract length was extended when demand fell short of the forecasted level and the operator encountered financial difficulties.

The above result highlights a cost of private finance, namely, the distortions in incentives that results from the need to modifying contract length away from the level that ensures optimal incentives.

Engel, Fischer and Galetovic (2001) also endogenize contract length in a setting where there is no moral hazard. The procedure they suggest is the Least Present Value Revenue (LPVR). The idea is to award a contract to the firm bidding the lowest LPVR and the contract ends when the LPVR is received. The tariff and the rate of discount (fixed or variable) are generally agreed at bidding stage or set in advance by G. If demand and tariffs adversely affect revenues, the concession runs for additional years until LPVR is secured. Since the firm is still residual claimant on cost saving, it provides incentives to operate at optimal costs because any gains are fully captured by $F$. LPVR should be used when $F$ cannot influence demand and in which objective quality standards can be set, measured, and enforced: example roads, landing strips in airports. 
Although a common wisdom is that contract length should be related to the life cycle of the investments sunk by the firm, what is the optimal contract length of a concession contract is an issues relatively unexplored by the economic literature. One exception is Ellman (2006) who emphasizes that the long-term nature of PPP contracts favors incentives by the government but it has a cost in terms of reduced flexibility. He showed that a longer contract length helps to protect the contractor from his investment being expropriated by the government but it reduces the incentives of the government to discover new service innovations since changes are costly to renegotiate. In Iossa and Martimort (2008) we also study the trade-off between incentives and flexibility though our focus is on investment by the firm in cost-reducing effort.

\section{Contractual Dynamics: the Trade-Off Between In- vestment and Maintenance}

PPP projects are typically long-term projects which might cover 20 to 35 years. Over a long lasting project where the quality of durable assets and infrastructures may significantly depreciate, an important issue concerns the extent to which contractors are willing to invest to improve the stock of existing infrastructure in the long-run or whether they prefer to choose management strategies that maintain costs low in the short-run.

To analyze the trade-off between investment and maintenance, we now assume that the firm gets a basic stock of infrastructure to provide public service on $G$ 's behalf at date $t=1$. Improving this stock requires some extra investment which costs $\frac{a^{2}}{2}$ today but this pays off tomorrow in terms of increasing demand by an amount $d a$. Another strategy would be to avoid incurring any initial investment and then increasing demand with more service quality.

Profits in each period are respectively given by:

$$
\pi_{1}=p_{0}\left(d_{0}+e_{1}+\eta_{1}\right)-\frac{a^{2}}{2} \text { and } \pi_{2}=p_{0}\left(d_{0}+d a+e_{2}+\eta_{2}\right)
$$

where the demand uncertainty $\eta_{i}(i=1,2)$ is normally distributed with zero mean and variance $\sigma^{2}$, and $e_{i}$ is effort in service quality undertaken at at date $i$. The demand shocks are assumed to be independent in the two periods. This assumes no cumulative effects due for instance to demand growth. Investing increases accounting costs in the short-run but, because of a positive externality between design and operation, increases demand by $d a$ with $d>0$. Implicit in our formulation is the fact that the cost of investment is not observable to $G$ meaning that it is (at least partly) aggregated with other costs, noticeably the first-period operating costs, in the firm's book. For simplicity, there is no discounting. We will also assume that the investment in infrastructure has some extra social benefit $b a$ that accrues to $G$ (this can be viewed as the residual value of the infrastructure at the end of the franchise). Assuming that investment is verifiable, its first-best level satisfies therefore:

$$
a^{F B}=p_{0} d+b
$$

Let us turn now to the case where the investment $a$ is non-verifiable and must be induced by $G$ through adequate incentives. Denote $t_{i}\left(\pi_{i}\right)=\alpha_{i}+\beta_{i} \pi_{i}$ the profit-sharing 
rule used at date $i{ }^{13}$ Let us first consider the case where $G$ can commit himself to such a two-period contract $\left\{t_{1}\left(\pi_{1}\right), t_{2}\left(\pi_{2}\right)\right\}$.

Still assuming a quadratic disutility of maintenance effort in each period, the firm chooses its whole array of actions $\left(a^{*}, e_{1}^{*}, e_{2}^{*}\right)$ to maximize its long-run expected payoff:

$$
\left(a^{*}, e_{1}^{*}, e_{2}^{*}\right)=\arg \max _{\left(a, e_{1}, e_{2}\right)} \sum_{i=1}^{2}\left(\alpha_{i}+\beta_{i} p_{0}\left(d_{0}+e_{i}\right)-\frac{e_{i}^{2}}{2}\right)-\beta_{1} \frac{a^{2}}{2}+\beta_{2} d p_{0} a .
$$

This leads to the following incentive constraints:

$$
e_{1}=\beta_{1} p_{0}, \quad e_{2}=\beta_{2} p_{0}, \text { and } \beta_{2} d p_{0}=\beta_{1} a .
$$

An interesting benchmark is obtained when $G$ offers the stationary contract with slope $\beta_{u}^{S B}$, i.e., the contract that would be optimal in the absence of any concern on the renewal of the infrastructure. This contract induces a stationary effort $e_{1}=e_{2}=\beta_{u}^{S B} p_{0}$ and an investment level, namely $a=d p_{0}$, which is privately but not socially optimal if $b>0$. There is too little investment in renewing infrastructure with such stationary contract. Raising this investment requires modifying the intertemporal pattern of incentives.

Result 5 Assuming full commitment to a long-term cost-reimbursement rule; the optimal long-term contract entails higher powered incentives towards the end of the contract than at the beginning and an inefficient level of investment:

$$
e_{1}^{S B}<e_{u}^{S B}<e_{2}^{S B}, \text { and } a^{S B}<a^{F B} .
$$

The intuition behind this proposition can be understood as follows. By offering costplus contracts in the earlier periods and fixed-price contracts towards the end of the relationship, $G$ makes $F$ bear less of the costs and enjoy most of the benefits associated to its non-verifiable investment. This boosts the firm's incentives to undertake the nonverifiable investment. Still, this is not enough to align the private incentives to invest with the socially optimal ones and underinvestment follows. ${ }^{14}$

The above result can be illustrated by the method of pricing for highway where price regulation generally evolves from cost plus to price cap (see e.g. the case of Italian highway). Urban public transport contracts also exhibit such patterns with a systematic move towards fixed price contracts.

Literature : The literature on intertemporal incentive problems under moral hazard is huge but most of it assumes separability between the benefits and costs of working on a project in different period stressing the role of history dependent contracts to smooth incentives. ${ }^{15}$

\footnotetext{
${ }^{13}$ For simplicity we rule out here the possibility that contract $t_{2}\left(\pi_{2}\right)$ depends on the first period realization of demand.

${ }^{14}$ In Iossa and Martimort (2008) we discuss how our results would change if we allowed for history dependent contracts in the spirit of Rogerson (1985). We also discuss the possibility of learning about costs, of growing demand over time or of investment depreciating over time.

${ }^{15}$ See Laffont and Martimort (2002, Chapter 8) and the references therein.
} 
Laffont and Tirole (1993, Chapter 8) proposed an adverse selection model with repeated auctions of incentive contracts which shares many features of our model, most noticeably the shift towards higher powered incentives over time. An incumbent firm invests in period 1 but, because of contract renewal, may lose the benefits of its investment if it is not granted the new contract for date 2 . They particularly focused on the necessary bias towards the incumbent as an incentive tool to secure investment and show that this bias matters all the more that investment is not easily transferable. A major result of their analysis is also that incentives to invest are fostered with incentive schemes which are higher powered over time. Our pure moral hazard model can be viewed as providing a simplified version of the same insight.

Dewatripont and Legros (2005) argue that ex ante competition between potential consortia may limit the extent of cost overruns and that introducing a third-party (typically outside shareholders or creditors) in a PPP contract may improve monitoring which limits cost overruns as well.

The systematic move towards fixed-price contracts over time is also studied in Gagnepain, Ivaldi and Martimort (2009) in the case of urban transportation. They give another rationale for such patterns of increasing subsidies based on the idea that those short-term contracts are renewed on the basis of earlier information on cost performances. Subsidies which are renegotiation-proof exhibit such patterns. Finally, this trend is observed in practice also because of a tendency towards more price cap regulation and less monitoring by governments to reduce red-tape.

\section{The Role of the Institutional Framework: Regula- tory and Political Risks}

A critical issues in PPPs is whether the public authority will face its responsibilities over the rules on prices, public obligations and so on that are specified in the contracts and that influence the value of the transaction. Private financing of big transport infrastructure makes investors especially vulnerable to opportunistic governments. First, the investment is largely sunk and may require a long period to be recouped; the assets cannot be moved elsewhere, if at all, except at great cost. Second, transport projects often provide services that are essential to consumers making choices related to tariffs levels highly politically sensitive. ${ }^{16}$

Governments generally agree to compensate investors for political risks, although in practice justifications for government actions are used to delay or prevent such payments. Thus, private investors generally assume the risks associated with dispute resolution and the ability to obtain compensation should the government violate the concession agreement. ${ }^{17}$

\footnotetext{
${ }^{16} \mathrm{~A}$ number of political motives have been proposed to explain the interests of the public-sector party itself in reneging PPP contracts. The government may increase its chances to be re-elected by expanding spending or by promoting investment in public works that create jobs and boost economic activity (Guasch, 2004). By reneging, the government may also circumvent the opposition's scrutiny and reap the political benefits resulting from higher present spending, e.g. a higher probability of being re-elected (Engel, Fisher and Galetovic, 2006).

${ }^{17}$ The focus of this section is on how the lack of commitment can lead to opportunism by governments which exploit the sunk nature of the firm's investment. Another, equally important, source of weak
} 
In Latin America and Caribbean Countries various episodes were observed where, once the investment was made, the government (possibly a different one) retreated on its promises, satisfying users demands to reduce tariffs or appropriating the investor's profits. Instances have also been recorded where the government passed legislation to nullify contractual clauses (see Guash, Laffont and Straub, 2006). Political risk has also played a crucial role in Central and Easter Europe. A major obstacle to the PPP policy in Hungary has been the frequent change in political attitudes towards PPPs and user tolls (see Brench, Beckers, Heinrich, and von Hirschhausen, 2005), as since 1990 each change in government resulted in a different attitude and a different institutional framework for PPPs. ${ }^{18}$

Regulatory risk discourages potential investors and raises the cost of capital and the risk-premium (higher tariffs, or smaller transfer price) paid for PPPs. The political controversy that surrounded the £16 billion London Underground project of 2002-03 made lenders nervous so that $85 \%$ of the debt had to be guaranteed by the public sector at a fairly late stage in the procurement process. The consequences for taxpayers were badly felt following the failure of one of the contractors. Guasch and Spiller (1999) estimate that the cost of regulatory risk ranges from 2 to 6 percent points to be added to the cost of capital depending on country and sector. An increase of 5 points in the cost of capital to account for the regulatory risk leads to a reduction of the offered transfer fee or sale price of about $35 \%$ or equivalently it requires a compensatory increase in tariffs of about $20 \%$.

Some observers have argued that a weak governance may go hand in hand with lack of training: In Latin American countries, governments often did not receive instruments adequate to their mandate (Guash, Laffont and Straub, 2006). To improve governance, a number of countries have created dedicated PPP units - centres of expertise - to manage the contract with the private contractor. ${ }^{19}$ These include for example the Central PPP Policy Unit in the Department of Finance 1 in Ireland, the Unita' Tecnica della Finanza di Progetto in Italy and the Partnership UK in the UK.

In the remainder of this section we briefly consider the scope and consequence of regulatory opportunism. The non-stationary path of incentives described in Result 5 is of course highly dependent on $G$ 's ability to commit to increase subsidies in the second period to reward F's initial investment. We assume now that such commitment power is absent and that renegotiation takes place at date 2 with $G$ still having all bargaining power at that stage and extracting, through an adequate fee, all surplus that $F$ could withdraw from renegotiation.

When date 2 comes along, $F$ 's investment $a^{0}$ is sunk and the second period cost reimbursement rule is renegotiated to reach the optimal trade-off between maintenance effort

commitment refers to contract renegotiation that favors the firm. Gagnepain, Ivaldi and Martimort (200) estimate a structural principal-agent model of contract renegotiation in the French urban transport sector and show that subsidies paid to operators increase over time during the duration of the contract, suggesting lack of commitment by public authorities.

${ }^{18}$ At more general level, Hammami, Ruhashyankiko and Yehoue (2006) find that private participation (in the form of PPP, privatization or traditional procurement) is more prevalent in countries with less corruption and with an effective rule of law.

${ }^{19}$ For a study of delegated contracting in PPPs see e.g. Bennett and Iossa (2006b). For a discussion on the role of a PPP Unit see Rachwalski and Ross (2008). 
and insurance that would arise in a static context, i.e., conditionally on the investment level $a^{0}$ which was previously sunk. This yields the standard expressions for the second period maintenance effort and the slope of the renegotiated incentive scheme:

$$
\beta_{2}^{0}=\frac{1}{1+r \sigma^{2}}
$$

Under limited commitment, $G$ can still adjust the second-period fixed-fee to extract all surplus of the firm given his expectation over the investment level $a^{0}$ at this date and, of course, expectations are correct in equilibrium.

Anticipating the slope of date 2 incentive scheme, and knowing also the slope of the first-period incentive scheme, $F$ chooses his investment so that

$$
\beta_{u}^{S B} d p_{0}=\beta_{1} a
$$

With an opportunistic principal, welfare is lower than with full commitment. Moreover, the second-period contract entails lower powered incentives than under full commitment because the second-period incarnation of $G$ does not take into account the impact of the contract he offers on the firm's incentives to invest at date 1. Since $e_{2}^{0}=e_{u}^{S B}<e_{2}^{S B}$, (12) implies that the firm enjoys less of the benefits of investment. To maintain incentives for investment, the firm must be even more reimbursed for its first-period costs than under full commitment which moves first-period incentives even further towards cost-plus contracts.

Result 6 With an opportunistic principal, investment is lower and cost-reimbursement rules are even more tilted towards cost-plus contracts in both periods than under full commitment:

$$
e_{1}^{0}<e_{1}^{S B}, \quad e_{2}^{0}<e_{2}^{S B} \text { and } a^{0}<a^{S B} .
$$

Literature : The model above considers a renegotiation led by the government with the possibility of breaking an initial agreement. In a sense, the intertemporal incentive scheme is thus closer to a sequence of short-term contracts. In a two-period principal-agent model with short-term contracting and pure adverse selection, Laffont and Tirole (1993, Chapter 9) formalized the so-called "ratchet effect". This effect refers to the possibility that an agent with a high performance today will tomorrow face a more demanding incentive scheme, an intertemporal pattern of incentives similar to the one highlighted in Sections 5 and 6 above. The ratchet effect leads to much pooling in the first period as the agent becomes reluctant to convey favorable information early in the relationship. In our model the emphasis is on moral hazard, and the corresponding pattern of incentives induces the agent to invest less in early periods. In the context of PPP contracts, this effect partially nullifies the benefits of bundling and suggests that PPPs should be preferred in stable institutional environments.

Closer to the analysis of Section 6 but still in a pure adverse selection framework, Aubert and Laffont (2002) analyzed the mechanism through which a government can affect future contracting by distorting regulatory requirements to take into account possible political changes and subsequent contract renegotiation. Assuming that the current contract binds all future governments, imperfect commitment yields two main distortions. 
First, the initial government will delay the payment of the information rent to the second period, thereby free-riding on the cost of producing a higher quantity and leaving higher rents. Second, the degree of information revelation in the first period will be strategically determined to affect the beliefs of the new government. ${ }^{20}$

\section{Conclusions}

The use of PPPs in transport is widespreading. Notwithstanding the policy relevance, still little theoretical and empirical work exists. In this paper we have reviewed and unified in a common and flexible framework the existing literature on PPPs that is relevant for transport economics in an attempt to fill this gap.

Our analysis has pointed out that the bundling of project phases that characterizes PPPs provides incentives to the private contractor to take into account the costs of longterm project, from building to maintenance and operation. When the externality across project stages is positive, this improves incentives and, through appropriate risk transfer, yields better infrastructure and service quality. Thus our analysis suggests that PPPs are more beneficial when a better quality of the infrastructure can significantly impact on benefits at the operational stage and when demand for the service is stable and easy to forecast. This points to the suitability of PPPs in the transport sector, where infrastructure quality is key and short-term demand is relatively stable.

We have seen that in a PPP contract, although this is not specific to PPPs, the contractor can be incentivized through the allocation of demand risk and the choice of contract length. In sectors such as transport, where users pay for the service and demand levels are affected by the contractor's effort, demand risk is optimally transferred to the contractor. Contract length should be longer for transport modes where demand risk is lower and where the capital investment is greater, as in the rail industry as opposed to maritime transport. Financially free-standing projects can bring the additional cost that contract length must be increased to allow the firm to recoup its initial investment, which results in excessive risk transfer. Thus, welfare under PPPs is higher when service quality is verifiable, demand risk is low or the firm can diversify risk, and when there are government contributions or the initial capital investment is low.

Bundling of project phases and long-term contracting allow PPPs arrangements to provide efficient long-term incentives and to optimize the trade-off between investment and insurance along the life of the project. This helps to incentivize the contractor but it requires institutions with strong commitment power. As the risk of regulatory opportunism increases, the case for PPPs is weaker.

An important issue that has been left out of the analysis is related to the procurement process for PPPs. Most PPP or PFI contracts are too complex to use the open or restricted procedure. In most PPPs, the contracting authority is unable to determine the technical specifications and the appropriate price level in advance. Therefore, until now the negotiated procedure has been the preferred solution for procuring PPP or PFI contracts. Current experience shows however that the procurement process for PPPs

\footnotetext{
${ }^{20}$ Other kinds of political risks have been considered in the literature. For instance, Che and Qian (1998) use the property rights approach to show that relinquishing firms' ownership to local governments may help in a context with insecure property rights where a national government may expropriate owners.
} 
has been costly and time consuming. Albeit with differences between sectors, it has been estimated that PPP tendering periods last an average of 34 months (NAO, 2007) and that procurement costs can reach 5-10\% of the capital cost of a project (Yescombe, 2007). ${ }^{21}$ Recently however the European Commission introduced the Competitive Dialogues, a new procedure for PPPs contracts (EU Directive 2004/18/EC ).

\footnotetext{
${ }^{21}$ These transaction costs are also to a large extent independent of the size of a project, which suffices to make PPP unsuitable for low capital value projects. The HM Treasury (2006) in the UK currently considers PFI projects for less than $£ 20 \mathrm{~m}$ as poor value for money.
} 


\section{References}

[1] Arthur Andersen and Enterprise LSE (2000), Value for Money Drivers in the Private Finance Initiative. London: The Treasury Taskforce.

[2] Aubert, C. and J.J. Laffont (2002), "Political Renegotiation of Regulatory Contracts," Mimeo IDEI, Toulouse.

[3] Aschauer, D. A. (1989), "Is Public Expenditure Productive?", Journal of Monetary Economics, 23: 177-200.

[4] Bajari, P. and S. Tadelis (2001), "Incentives versus Transaction Costs: A Theory of Procurement Contracts," RAND Journal of Economics, 32: 387-407.

[5] Bennett, J. and E. Iossa (2006a), "Building and Managing Facilities for Public Services," Journal of Public Economics, 90: 2143-2160.

[6] Bennett, J. and E. Iossa (2006b), "Delegation of Contracting in the Private Provision of Public Services," Review of Industrial Organization, 29: 75-92 Special Issue on Public-Private Partnerships.

[7] Besley, T. and M. Ghatak (2001), "Government versus Private Oownership of Public Goods," Quarterly Journal of Economics, 116: 1343-1372.

[8] Blanc-Brude, F., H. Goldsmith and T. Välilä(2006), "Ex Ante Construction Costs in the European Road Sector: A Comparison of Public-Private Partnerships and Traditional Public Procurement,"European Investment Bank, Economic and Financial Reports 2006/01.

[9] Brench, A., T. Beckers, M. Heinrich, and C. von Hirschhausen, (2005), "PublicPrivate Partnerships in New EU Member Countries of Central and Eastern Europe," European Investment Bank, Vol 10, n.2.

[10] CBO, Congressional Budget Office (2007), "Trends in Public Spending on Transportation and Water Infrastructure, 1956 to 2004," Congressional Budget Office, Pub.No. 2880.

[11] Che, J. and Y. Qian (1998), "Insecure Property Rights and Government Ownership of Firms," Quarterly Journal of Economics, 113: 467-496.

[12] Dewatripont, M. and P. Legros (2005), "PPPs: Contract Design and Risk Transfer," European Investment Bank Papers, 10: 120-141.

[13] EC, EC White Paper (2006)."

[14] EIB, European Investment Bank (2004), "The EIB's role in Public-Private Partnerships (PPPs)."

[15] Ellman, M. (2006), "The Optimal Length of Contracts with Application to Outsourcing," Discussion Paper Universitat Pompeu Fabra. 
[16] Engel, E., R. Fisher and A. Galetovic (2001), "Least Present Value of Revenue Auctions and Highway Franchising," Journal of Political Economy, 105: 993-1020.

[17] Engel, E., R. Fisher and A. Galetovic (2006), "Renegotiation Without Holdup: Anticipating Spending in Infrastructure Concessions," Cowles Foundation Discussion Paper 1567.

[18] Estache, A., Guash, JL., Imi, A. and Trujillo, L. (2008), "Multidimensionality and Renegotiation: Evidence from Transport-Sector Public-Private-Partnership Transactions in Latin America," World Bank Policy Research Working Paper No. 4665

[19] Estache, A., Juan E. and Trujillo, L. (2008), "Public-Private Partnerships In Transport," World Bank Policy Research Working Paper No. 4436

[20] European Commission (2004). Resource Book on PPP Case Studies. Directorate General Regional Policy.

[21] Francesconi, M. and A. Muthoo (2006), "Control Rights in Complex Partnerships," Mimeo.

[22] Gagnepain, P. Ivaldi, M. and Martimort D., (2009), The Cost of Contract Renegotiation For Public Transport Services. Discussion papers, Toulouse School of Economics.

[23] Grout, P. (1997), "The Economics of the Private Finance Initiative," Oxford Review of Economic Policy, 13: 53-66.

[24] Guasch, J.L. (2004), "Granting and Renegotiating Infrastructure Concenssions: Doing it Right," WBI Development studies, the World Bank.

[25] Guasch, J.L. and P. Spiller (1999), "Managing the Regulatory Process: Design, Concepts, Issues and the Latin America and Caribbean Story," The World Bank, Washington, D.C.

[26] Guasch, J.L., J.J. Laffont and S. Straub, (2006) "Concessions of Infrastructure in Latin America: Government-led Renegotiations," forthcoming Journal of Applied Econometrics.

[27] Hammami, M., J.F. Ruhashyankiko and E.B. Yehoue (2006), "Determinants of Public-Private Partnerships in Infrastructure," Working Paper No 06/99, International Monetary Fund.

[28] Hart, O. (2003), "Incomplete Contracts and Public Ownership: Remarks and an Application to Public-Private Partnerships," Economic Journal, 119: 69-76.

[29] Hart, O., A. Shleifer and R. Vishny (1997), "The Proper Scope of Government: Theory and an Application to Prisons," Quarterly Journal of Economics, 112: 111958.

[30] HM Treasury (2006), Strenghtening long-term partnerships. London: HM Treasury. 
[31] Holmström, B. and P. Milgrom (1991), "Multi-Task Principal-Agent Analyses: Incentive Contracts, Asset Ownership, and Job Design," Journal of Law, Economics and Organization, Special Issue, 24-52.

[32] Iossa, E., and Martimort, D. (2008), "The Simple Micro-economics of Public Private Partnerships," mimeo Toulouse School of Economics.

[33] IPPR, Institute for Public Policy Research (2001), Building Better Partnerships. London: Institute for Public Policy Research.

[34] Laffont, J.J. and D. Martimort (2002), The Theory of Incentives: The PrincipalAgent Model, Princeton University Press.

[35] Laffont, J.J. and J. Tirole (1993), A Theory of Incentives in Procurement and Regulation, MIT Press.

[36] Lewis, T. and D. Sappington (1995), "Optimal Capital Structure in Agency Relationships," RAND Journal of Economics, 26: 343-361.

[37] Martimort, D. and J. Pouyet (2008), "Build It Not: Normative and Positive Theories of Public-Private Partnerships," International Journal of Industrial Organization, Special Issue on PPPs , 26: 393-411.

[38] Martimort, D. and W. Sand-Zantman (2007), "Signalling and the Design of Delegated Management Contracts for Public Utilities," Rand Journal of Economics, 37: 763-782.

[39] Megginson, W. and J. Netter (2001), "From State to Market: A Survey of Empirical Studies on Privatization," Journal of Economic Literature, 39: 321-389.

[40] Messina, G. (2008), "Time is money: measuring transport infrastructures from the new economic geography perspective." Bank of Italy- Research Department

[41] NAO, National Audit Office (2007). Improving the PFI Tendering Process. London: National Audit Office, HC149.

[42] Pollock, A. and N. Vickers (2000), "Private Pie in the Sky," Public Finance, 14-20: $22-23$.

[43] Private Finance Journal, September 2008.

[44] Rachwalski, M. D. and Ross, T.W. (2008), "Running a Government's P3 Program: Centralized Agency or Line Departments?".Mimeo, University of British Columbia

[45] Ray, K. (2007), "Performance Evaluations and Effcient Sorting," Mimeo, Graduate School of Business, University of Chicago.

[46] Rosenau, P. V., ed. (2000). Public-Private Policy Partnerships, MIT Press, Cambridge Mass. and London.

[47] Sappington, D. and J. Stiglitz (1987), "Privatization, Information and Incentives," Journal of Policy Analysis and Management, 6: 567-582. 
[48] Yescombe, E. (2007), Public Private Partnerships: Principles of Policy and Finance, Elsevier. 